\title{
Adjusting residual stresses by flexible stress superposition in incremental sheet metal forming
}

Received: 16 October 2020 / Accepted: 22 February 2021 / Published online: 22 March 2021

(C) The Author(s) 2021

\begin{abstract}
Process-induced residual stresses significantly influence the mechanical properties of a formed component. A polymer pad is used as a flexible die in two-point incremental forming to induce compressive residual stresses in the component during the forming process. Experimental and numerical results illustrate the influence of compressive stress superposition on the component properties. It is shown that the active support, using a geometry-independent polyurethane die, causes beneficial compressive residual stresses on the tool side compared to the tensile residual stresses induced by the single-point incremental forming process without such a supporting die.
\end{abstract}

Keywords Two-point incremental forming $\cdot$ Flexible die $\cdot$ Residual stress $\cdot$ X-ray diffraction

\section{Introduction}

\subsection{Incremental sheet forming}

Incremental sheet forming (ISF) is a flexible manufacturing process that is particularly suitable for small batch sizes and rapid prototyping [1]. In ISF, a sheet metal, that is clamped at the edges, is continuously formed by the predefined movement of a hemispherical forming tool until the target geometry is achieved. As an advantage, the tool movement can be carried out by a conventional CNC milling machine [2]. During the forming process, only a small area of the sheet is in contact with the tool. Due to the localized deformation zone, very high strains occur locally [3]. Since the patenting of the process by Leszak in 1967 [4], different variants of the incremental sheet forming process were developed. The most important process variants are single-point incremental forming (SPIF) and two-point incremental forming (TPIF) (Fig. 1).

In the SPIF process (Fig. 1a), the sheet metal is formed on one side using the geometry-independent forming tool. The dieless SPIF process results in a high degree of flexibility, since the design and the costintensive manufacturing process of a die can be eliminated. Due to the springback effects and the lack of a rigid support on the non-tool side, the geometric accuracy of the manufactured workpieces produced with the SPIF is comparatively poor.

The TPIF process (Fig. 1b) developed by Matsubara [5] can improve the geometric accuracy of the manufactured components by using supporting dies [6]. By using dedicated solid dies, the TPIF process is less flexible than SPIF [7]. In contrast to the SPIF process, the tool is moving from the inside to the outside, while the guided clamping frame moves continuously downward (Fig. 1b). In the case of TPIF, the sheet is supported on the non-tool side either by a partial or full die or by a second forming tool. The full die can be in positive or

F. Maaß $(\varangle) \cdot$ M. Hahn · A. E. Tekkaya

Institute of Forming Technology and Lightweight Components, TU Dortmund University, Baroper Str. 303, 44227 Dortmund, Germany

e-mail: fabian.maass@iul.tu-dortmund.de 
(a)

SPIF

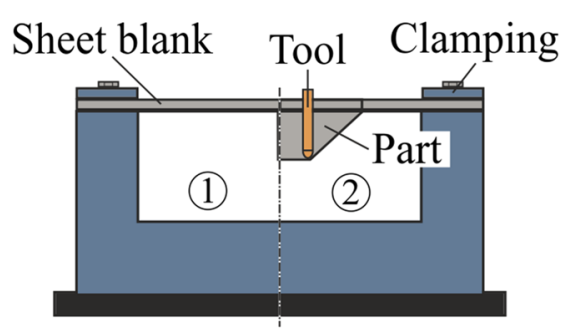

(1) before / (2) after forming (b)

\section{TPIF}

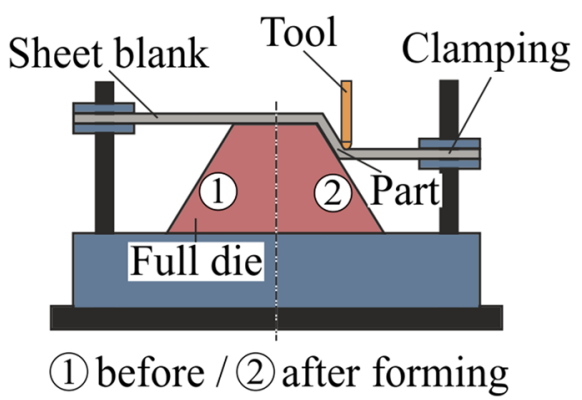

Fig. 1 a SPIF process; $\mathbf{b}$ TPIF process with full die

in negative direction to support the sheet metal from the non-tool side during the forming process [8]. These variants offer the possibility of manufacturing complex components with high geometric accuracy. The TPIF processes using a second forming tool or a partial die are more flexible compared to the TPIF using a full die.

In addition to TPIF with rigid dies, the use of flexible dies is gaining increasing interest. It can be distinguished between adjustable full and partial dies as in [9] and active or passive medium dies. The media can be polyurethane, oil or other viscous media, or compressed air.

The use of a rubber die for the TPIF process is described by [10]. In this publication, the rubber material is used as a geometry-dependent positive die to support a multi-point die system. The rubber pad was primarily used to improve the component's surface quality between the multi-point pins and the sheet metal. Rubber as a die material is cheap and easy to machine. Yet, used as a geometry-dependent full die, this approach is not beneficial in case of flexibility, especially compared to the SPIF process.

\subsection{Residual stress state}

Residual stresses in metal components can be induced thermally or by inhomogeneous plastic deformation during forming processes. Due to the incremental character, the process parameters in ISF can be adjusted locally during the entire process, in contrast to most conventional forming processes. Incremental sheet forming, therefore, offers the possibility of adjusting the forming-induced residual stresses to optimize the component properties such as geometric accuracy and fatigue strength.

In a recent publication, it is shown how the residual stress state can be influenced by setting the process parameters of incremental forming processes in truncated cones made of aluminum. A targeted-induced residual stress state can have positive effects on the product properties. For example, high tensile residual stresses perpendicular to the tool path direction on the tool side of the component can lead to a reduced fatigue strength and should therefore be avoided [11].

The aim of this paper is to provide a new approach for adjusting the residual stress state of components manufactured by incremental forming. The SPIF process setup is enhanced by a rubber pad as a flexible support to superpose compressive stresses in the sheet thickness direction during the forming process. Preliminary numerical investigations suggested the suitability of this approach. The clamped sheet metal is formed into a geometry-independent polyurethane die by the tool movement. The polyurethane pad serves as a flexible negative die, so the components can be manufactured without the need for designing and producing a specific die. The pressure of the die has a local effect on the sheet metal due to the acting tool force. The two-sided tool and die contact are limited to the forming zone. Therefore, this process is similar to a TPIF, in contrast to multi-point incremental forming (MPIF), where the geometry-dependent die is active at several points during the forming process.

Experimental results are presented for geometrically identical truncated cones, which were produced using both SPIF and the flexible TPIF. To compare the two process variants, the process forces, geometry, sheet thickness, and material hardness of the components are compared. In addition, process stresses were examined numerically and the residual stress states were determined experimentally. 

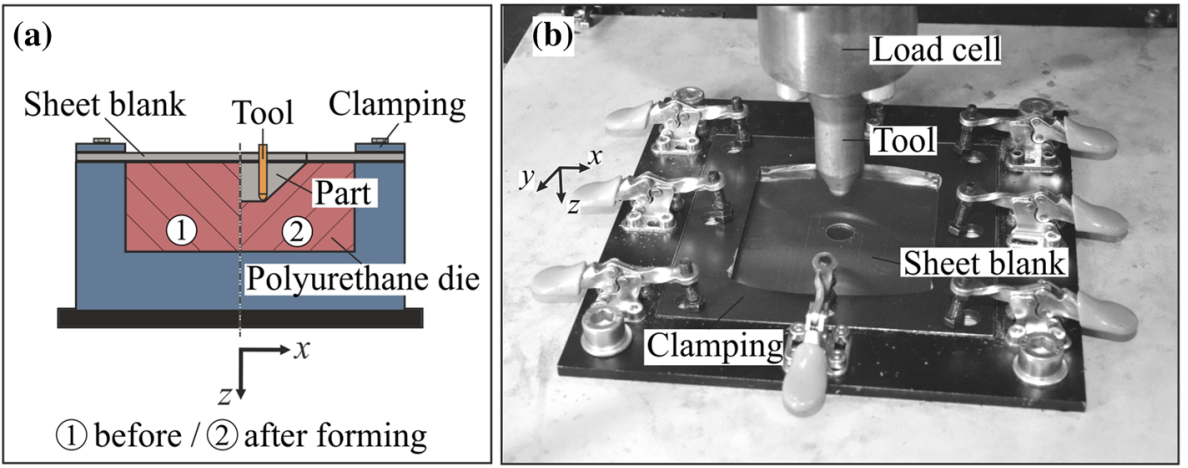

Fig. 2 a TPIF process using flexible polyurethane die; b TPIF experimental setup

Table 1 Material parameters Polyurethane D44

\begin{tabular}{lllll}
\hline Property & Hardness shore A DIN 53505 & Density & Tensile strength DIN 53504 & $\begin{array}{l}\text { Tensile strain at break DIN } \\
53504\end{array}$ \\
\hline Symbol & - & & $\sigma_{M}$ & $\varepsilon_{M}$ \\
Value & $72^{\circ} \pm 5 \mathrm{Sh} \mathrm{A}$ & $1.24 \mathrm{~g} / \mathrm{cm}^{3}$ & $46 \mathrm{MPa}$ & $550 \%$ \\
\hline
\end{tabular}

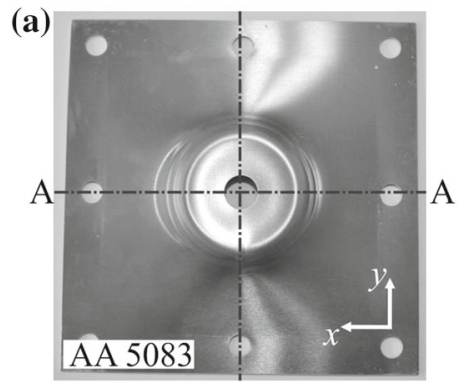

(b)

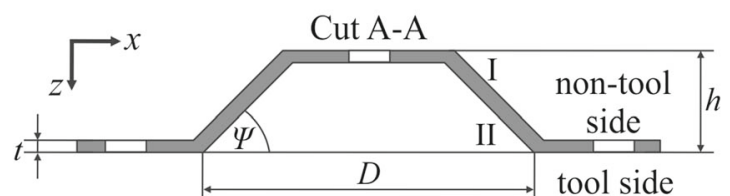

Fig. 3 a TPIF manufactured truncated cone geometry; $\mathbf{b}$ dimension of the specimen

\section{Process description and setup}

A description of the process principle for the compressive stress-superposed incremental sheet forming by means of polyurethane die (TPIF) is described in Fig. 2a. The process setup for the SPIF process is enhanced to a TPIF process by integrating a polyurethane plate. A polyurethane die is placed below the unprocessed sheet metal. The polyurethane die is installed by form-fit joints and fixed in all special directions (see (1) Fig. 2a). The positioned and clamped sheet metal is formed into the polyurethane die by the forming tool movement in $z$-direction (see (2) Fig. 2a). The combination of blank holder and polyurethane die is installed in a 5-axis DMU 50 milling machine from DMG Moriß. The tool movement is carried out by the computer numerical control of the milling machine and the process forces are measured by a three-component load cell. The experimental setup is shown in Fig. 2b.

A polyurethane plate made of PU D44 material is used. The dimension of the die is $90 \times 90 \times 50 \mathrm{~mm}$. The material is characterized by high abrasion resistance and good damping properties. The material data according to the manufacturer can be found in Table 1.

The blank material is aluminum AA5083 in H111 condition with an initial sheet thickness of $t_{0}=1 \mathrm{~mm}$. The laser-cut square sheet has the dimensions $130 \times 130 \mathrm{~mm}$. The initial yield stress of the material is determined by a tensile test to be $\sigma_{\mathrm{f}, 0}=165 \mathrm{MPa}$.

A truncated cone geometry as shown in Fig. 3a serves as a reference geometry to compare the compressive stress-superposed incremental sheet forming process (TPIF) with a SPIF process. The dimensions of the truncated cone geometry are the diameter of the cone $D=60 \mathrm{~mm}$ with a wall angle $\Psi=40^{\circ}$ and a final cone height of $h=6 \mathrm{~mm}$ according to the notation in Fig. $3 \mathrm{~b}$. 
Table 2 Process parameters

\begin{tabular}{lllll}
\hline Process & Step-down & Tool diameter & Tool rotation & Feed rate \\
\hline Symbol & $\Delta z$ & $D_{\text {Tool }}$ & $\theta_{\text {Tool }}$ & $v_{\text {Tool }}$ \\
Value & $2 \mathrm{~mm}$ & $10 \mathrm{~mm}$ & $300 \mathrm{RPM}$ & $600 \mathrm{~mm} / \mathrm{min}$ \\
\hline
\end{tabular}

(a)

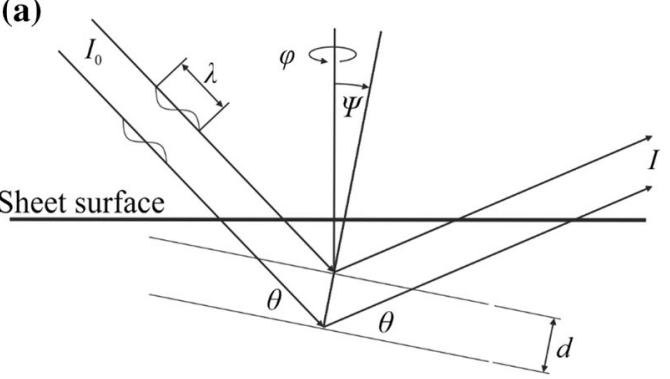

(b)

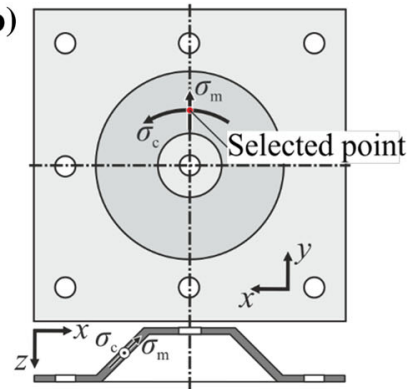

Fig. 4 a XRD measurement method; $\mathbf{b}$ top view, truncated cone geometry with measuring point

The process parameters for the manufacturing process of the cone for the SPIF and the TPIF process are illustrated in Table 2. The driven forming tool with a hemispherical tool tip is moved along a bidirectional tool path with an equidistant tool step-down $\Delta z$. The tool path and tool path strategy for SPIF and TPIF are the same. Tool rotation is used to reduce friction and resulting tool wear to provide a decrease in forming forces and a reduction of surface roughness as described in [12]. Preliminary tests showed a higher forming depth $h$ for the TPIF process. To generate identical geometries and comparable results with both processes, three different specimens are manufactured. While all other process parameters are kept constant according to Table 2, three different forming depths are analyzed. Two specimens with three step-down increments and a final forming depth of $h=6 \mathrm{~mm}$ for SPIF respectively TPIF. Additionally, a specimen with a four step-down increments, a wall angle $\Psi=40^{\circ}$, and a final forming depth of $h=8 \mathrm{~mm}$ for the SPIF process was manufactured to compensate the higher springback of the SPIF specimen compared to the TPIF specimen. The SPIF specimen with the higher forming depth is labeled as 'SPIF compensated.' Three specimens of each specification are manufactured. The edges of the sheet are clamped during the forming process. Deep-drawing oil Castrol ${ }^{\circledR}$ Iloform PN 226 was applied to the blank to reduce wear. The process forces for manufacturing truncated cones with the SPIF, SPIF compensated and the TPIF process are measured experimentally using a three-component force sensor. The forming forces are recorded and evaluated using HBM® Catman Easy software.

\subsection{Residual stress measurement}

The residual stress measurements are carried out using non-destructive X-ray diffraction. An X-ray diffractometer Xstress G2R from Stresstech GmbH ${ }^{\circledR}$ is used to measure the near-to-surface residual stresses. The strain analysis is based on the determination of the interplanar distance $d\{h k l\}$ (hkl-Miller indices) according to the Bragg law shown in Fig. $4 \mathrm{a}$ and Eq. 1. Here, $n$ is the order of diffraction of the interference $\{h k l\}, \lambda$ is the wavelength, and $\theta$ is its Bragg angle.

$$
n \cdot \lambda=2 \cdot d_{\{h k l\}} \cdot \sin \theta
$$

The residual stresses are measured in the middle of the cone wall at a height of $h_{\mathrm{XRD}}=3 \mathrm{~mm}$. With the tool side and the non-tool side, both sides of the cone wall are evaluated. The selected point of evaluation is shown in Fig. 4b. The residual stresses are measured in circumferential $\sigma_{\mathrm{c}}$ and meridional $\sigma_{\mathrm{r}}$ direction. The interplanar grid spacings for different sample orientations are measured according to the tensor character of strains and stresses. The stresses are calculated using the $\sin ^{2} \Psi$ method [13]. Co-K $\alpha$ radiation with a penetration depth of $\tau=5 \mu \mathrm{m}$ is used. The $2 \theta$ angle has a range of $-42^{\circ}-42^{\circ}\left( \pm 3^{\circ}\right.$ oscillation $)$. A collimator with a $2 \mathrm{~mm}$ spot size is used. The exposure time is $t=20 \mathrm{~s}$ per step. The reflection profiles are recorded for the $9 \Psi$-inclinations $\left(0^{\circ}, \pm 18.7^{\circ}, \pm 27^{\circ}, \pm 33.8^{\circ}, \pm 40^{\circ}\right)$. The resulting stresses are mean values of three repeated measurements. 

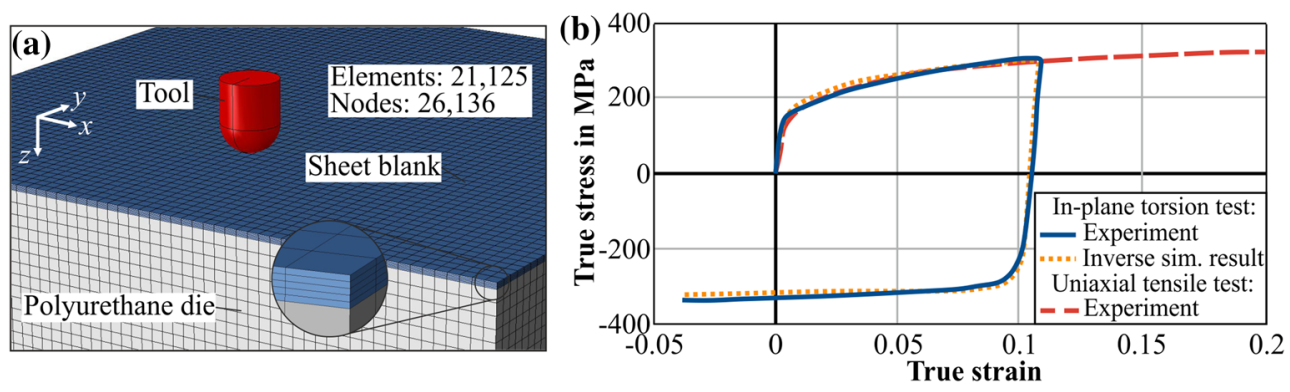

Fig. 5 a Numerical process model; b material characterization of aluminum alloy 5083

\subsection{Numerical process model}

A finite element model was built according to the experimental setup as in Fig. 2b. The numerical forming process replicated in Abaqus ${ }^{\circledR}$ consists of the forming tool, the sheet blank, and the polyurethane die as shown in Fig. 5a. The forming tool is modeled as a rigid body. All deformable parts consist of solid elements (C3D8I). The solid elements have an edge length of $1 \mathrm{~mm}$. Five elements over the sheet thickness are used for the sheet blank. Twenty-five elements over the thickness are used for the polyurethane die. A mesh sensitivity study was performed. The selected element size is optimum in terms of quality of results and required computing time. The process model is explicitly time integrated with a time step of $1 \times 10^{-06} \mathrm{~s}$. The material model for the sheet metal includes combined isotropic-kinematic hardening. A penalty contact is used for the interaction of forming tool and sheet. The combined isotropic-kinematic hardening model also includes the possibility of cyclic hardening, as it occurs with cyclically loaded parts, based on Lemaitre and Chaboche [14]. In-plane torsion testing was used to characterize the base material as shown in Fig. 5b. The cyclic hardening parameters are determined inversely as $Q^{\infty}=83 \mathrm{MPa}$ and $b=9.88$ using the cyclic loading test results as described in [15]. The initial flow stress of the AA5083 material is $\sigma_{\mathrm{f}, 0}=165 \mathrm{MPa}$. For the polyurethane die base material, a hyperelastic material model is used based on Mooney-Rivlin [16]. The material parameters are determined by tensile tests to.

$$
C_{10}=1.92 \text { and } C_{01}=0.97 \text {. }
$$

\section{Results}

\subsection{Geometric accuracy}

The geometries of the manufactured cones are measured in unclamped condition by the 3D-digitalizer GOM ${ }^{\circledR}$ ATOS II using ATOS Professional V8 SR1 software for evaluation. The geometric accuracy compared to an ideal (CAD) truncated cone geometry is plotted in Fig. 6 for the TPIF, SPIF, and SPIF compensated process. The geometric deviation is the distance between the actual and ideal geometry in the surface-normal direction of the actual geometry. For the TPIF process in Fig. 6a, a significant difference in the geometry is observed in comparison with the SPIF geometry in Fig. 6c. A much higher geometric deviation occurs in the SPIF geometry, especially in the bottom area of the truncated cone. The overall arithmetic mean deviation for the SPIF part is $\bar{x}$ $=1.35 \mathrm{~mm}$ compared to $\bar{x}=0.57$ for the TPIF geometry. To equalize the geometric deviation, a compensated SPIF part is manufactured with a higher forming depth $h=8 \mathrm{~mm}$. The resulting compensated SPIF geometry is shown in Fig. 6b. The geometries of the TPIF and the geometrically compensated SPIF process are in satisfying agreement, as the overall arithmetic mean value for the TPIF of $\bar{x}=0.57$ and compensated SPIF part of $\bar{x}=0.65$ are comparable. The bottom area of the TPIF geometry is less uniform compared to the SPIF geometry, due to the polyurethane die, that pushes the already formed areas of the cone and slightly shifts the cone geometry.

A comparison of all three geometries is plotted in Fig. 7. The cut view according to Fig. 6a illustrates the geometric deviation between the truncated cone geometries and the ideal truncated cone geometry. A significant difference between the TPIF and SPIF geometry occurs in the bottom area of the cone. For the TPIF and SPIF compensated geometries, the forming depth in the bottom area is almost equal to the target geometry. The SPIF component shows a similar geometry in the wall area of the component but significant geometrical deviation in the bottom area. 

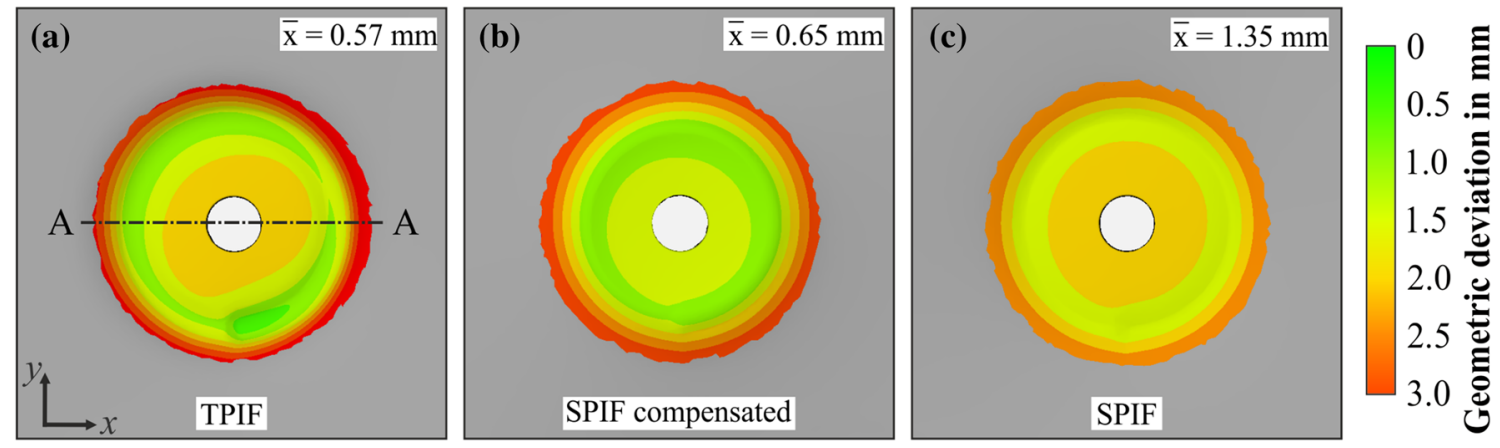

Fig. 6 Geometric deviation of a TPIF; b SPIF compensated and $\mathbf{c}$ SPIF components

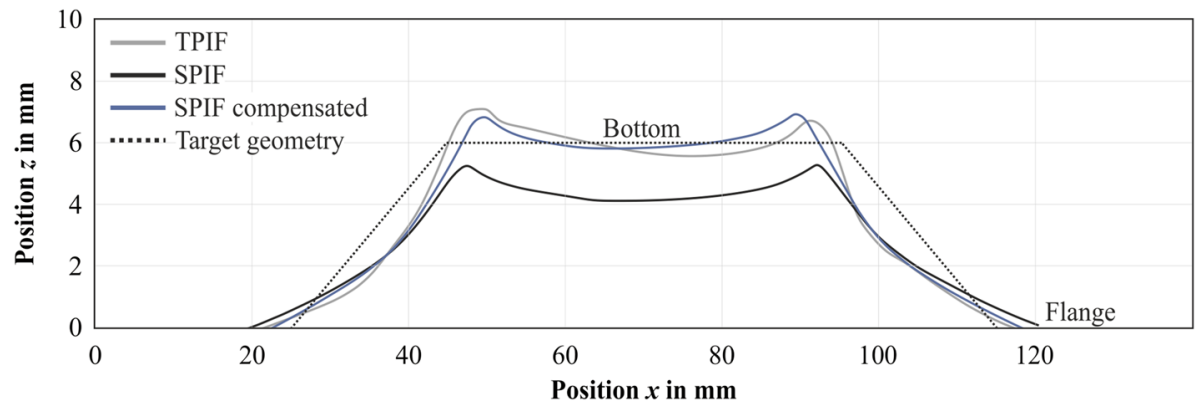

Fig. 7 Comparison of cut A-A truncated cone geometries

\subsection{Process forces}

Figure 8a shows the recorded forming force in $z$-direction. The forming force for the SPIF process is increasing with each tool step-down. Compared to the forming force of the TPIF process, the qualitative curve progression is equal to the SPIF process. The amplitudes of the forming forces are significantly higher for the TPIF process compared to the SPIF process forces. A comparison of the maximum forming forces during the whole forming process in $x$-, $y$ - and, $z$-direction is plotted in Fig. 8b. The maximum forming force in $z$-direction for the SPIF process $(F \mathrm{z}, \max =0.79 \mathrm{kN})$ is $79 \%$ higher in the comparable TPIF experiment $(F \mathrm{z}, \mathrm{max}=1.8 \mathrm{kN})$. The process forces in $x$ - and $y$-direction are continuously increasing with each step. The maximum process forces in $x$ - and $y$-direction, which occur in the last steps, are nearly equal for each forming process due to the symmetric circular tool path. In SPIF, the maximum amount of force in $x$ - and $y$-direction is only $43 \%$ of the maximum force in $z$-direction. Compared to the process variant with a supporting polyurethane die, the maximum amount of force in $x$ - and $y$-direction for the TPIF is $78 \%$ of the maximum force in $z$-direction. A significant increase in all force components occurs in TPIF compared to SPIF. The force output in $z$-direction of the TPIF numerical model as presented in Fig. 8a shows a satisfactory agreement with the experimental results.

\subsection{Sheet thickness and material hardness}

An evaluation of the sheet thickness is done in the selected point in the middle of the cone wall (Fig. 4b). All specimens are cut in meridional direction in the selected point. Stripes are extracted from this area and cold-mounted for microscopy. Pictures of the microscopy showing the sheet thickness can be found in Fig. 9 . The sheet thickness values are mean values of three repetitions.

A comparison of the sheet thickness in the cone wall for the three process variants can be seen in Fig. 10a. The measured thickness of the initial base material is around $t_{0}=0.97 \mathrm{~mm}$. A sheet thickness reduction occurs for all process variants. The smallest thickness reduction of $6 \%$ is observed for the SPIF process compared to the initial sheet thickness. The thickness reduction of $15 \%$ for the TPIF process is significantly higher. Yet, overlapping exists due to scattering. 
(a)

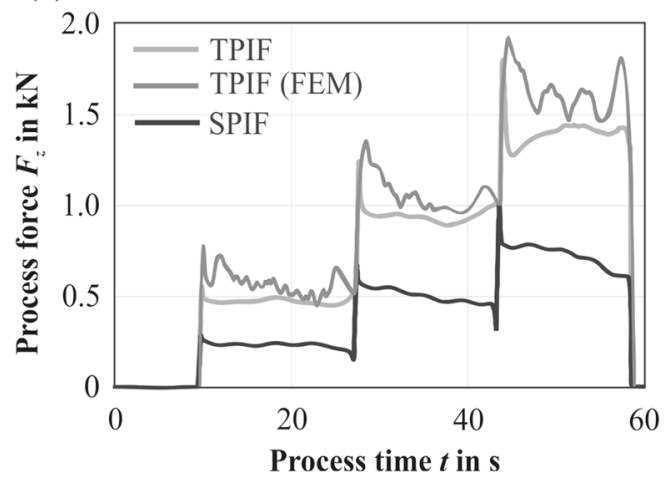

(b)

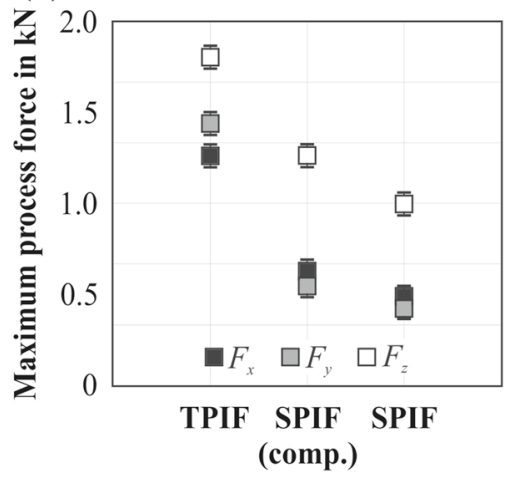

Fig. 8 a TPIF and SPIF process forces; $\mathbf{b}$ maximum process forces
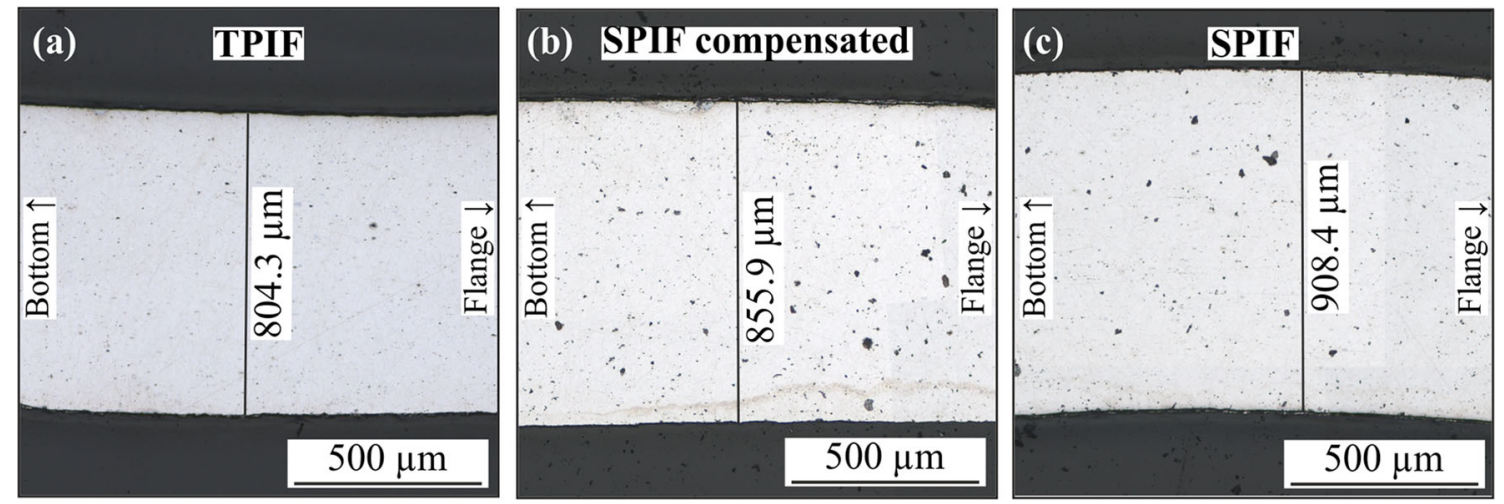

Fig. 9 Evaluation of sheet thickness for a TPIF; $\mathbf{b}$ SPIF compensated and $\mathbf{c}$ SPIF process

(a)

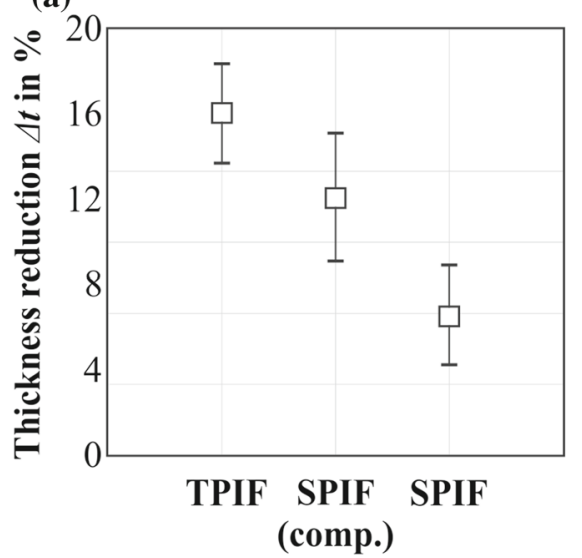

(b)

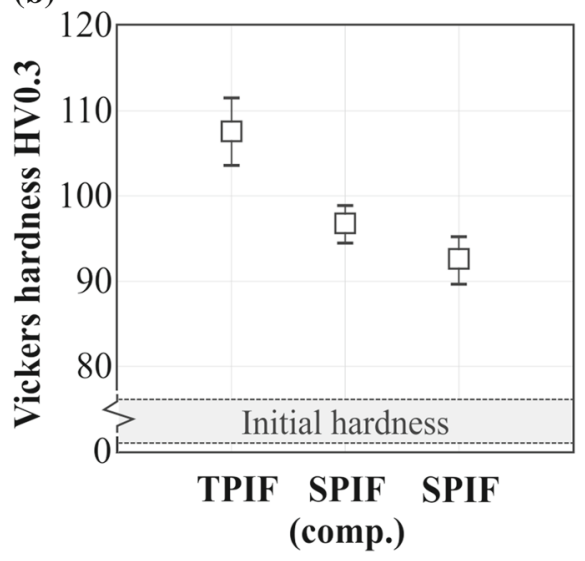

Fig. 10 a Sheet thickness reduction; b material hardness

Beside the sheet thickness, the material hardness is measured in the cross section of the cone wall in the selected point using Vickers hardness HV0.3 (Fig. 4b). All hardness values are mean values of three measurements. The initial material hardness of the AA5083 base material is measured to be $74 \pm 3 \mathrm{HV} 0.3$. After the forming processes, all specimens have a significantly higher material hardness in the forming zone compared to the initial material hardness. The specimen with the highest thinning (TPIF) shows the highest increase in material hardness of $31 \%$. In the forming zone of the SPIF specimen, the lowest material hardening of $20 \%$ occurs. 


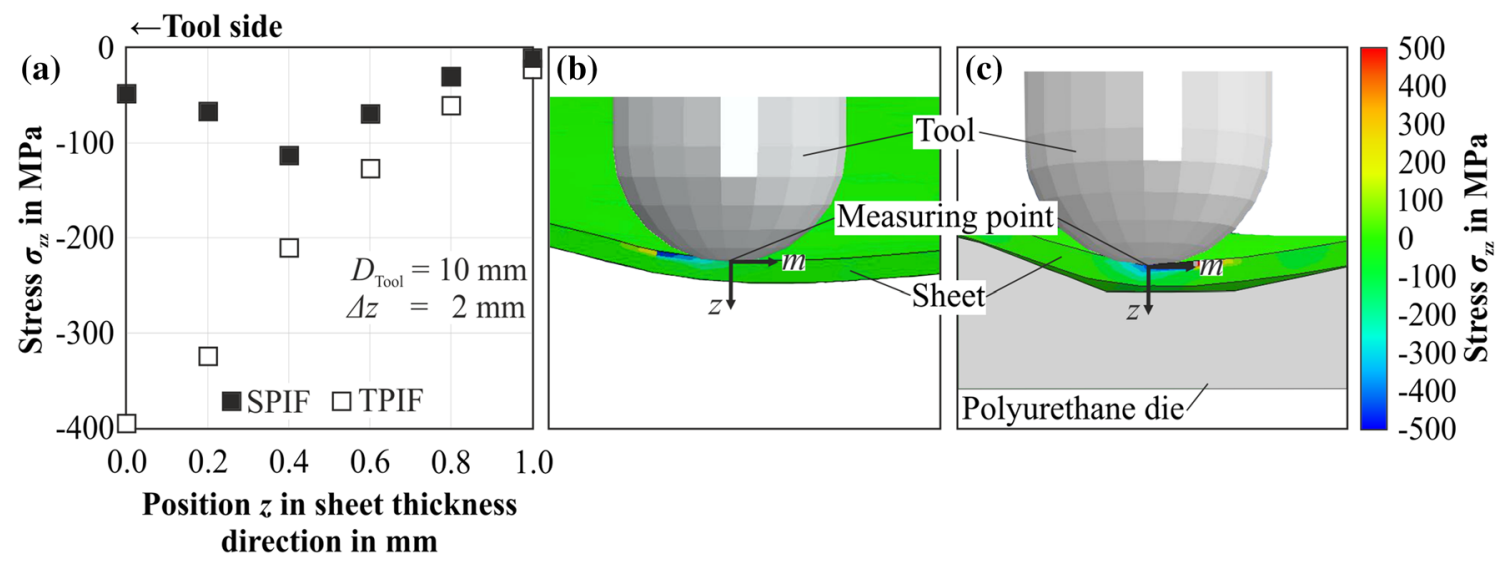

Fig. 11 a Stresses in sheet thickness direction due to compressive stress superposition; b SPIF; c TPIF

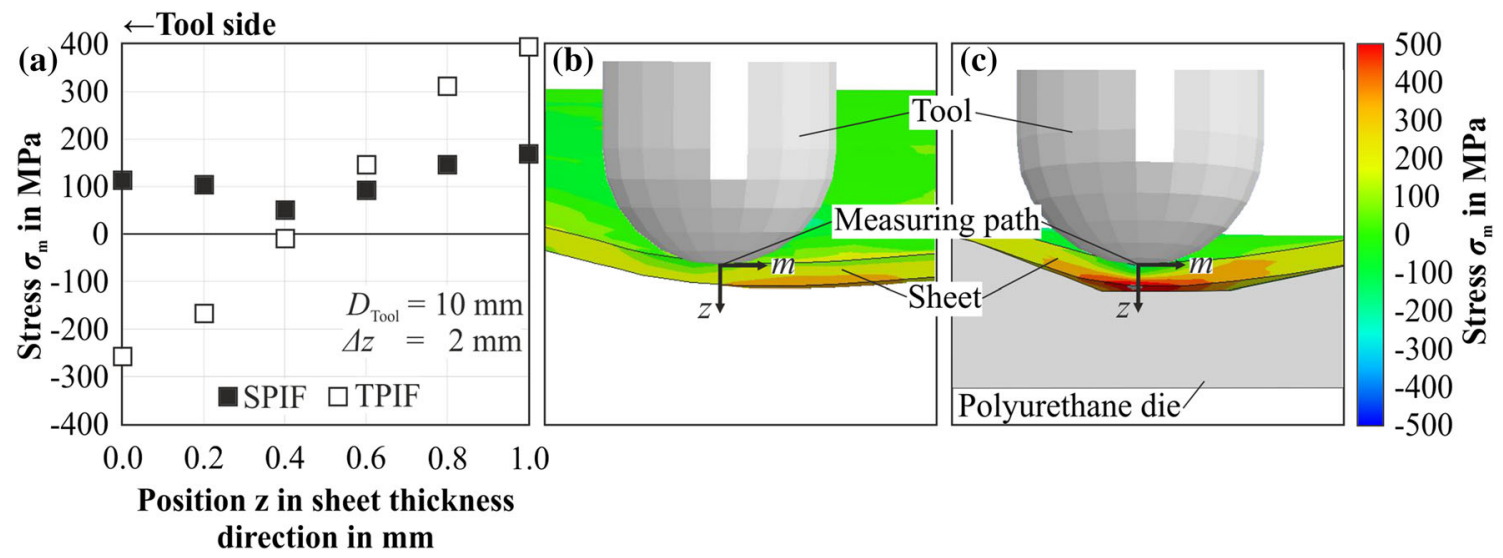

Fig. 12 a Stresses in meridional direction due to compressive stress superposition; b SPIF; $\mathbf{c}$ TPIF

\subsection{Superposition of compressive stresses}

The influence of the additional compressive stresses during the forming process is analyzed by the numerical model. As shown in Fig. 11a, the use of a supporting polyurethane die changes the stress state $\sigma_{\mathrm{zz}}$ in through-thickness direction of the sheet. Especially, on the tool side, the compressive stresses are increased by the additional support resulting in eight times higher compressive stresses under the forming tool. The TPIF characteristics of the process can be supported by the numerical results. The additional support of the polyurethane die is only active where it is locally deformed by the forming tool (Fig. 11c).

An evaluation of the stresses in meridional direction is plotted in Fig. 12a. Compared to the stress throughthickness characteristic in the SPIF process (Fig. 12b), the TPIF process shifts the decreases the stresses on the tool side and increases the stresses on the non-tool side. High compressive stresses $\sigma_{\mathrm{r}}$ are measured in the meridional direction under the forming tool.

\subsection{Residual stress state}

The determined residual stress state of the formed components is plotted in Fig. 13. Each data point equals the mean value of three repeated measurements. The measured residual stresses of the initial base material can be neglected as they are $<5 \mathrm{MPa}$. According to Fig. $4 \mathrm{~b}$, the residual stresses of all three specimens are evaluated in the middle of the cone wall on both sides.

The measured residual stresses in meridional direction (Fig. 13a) at the tool side significantly differ for the three process variants. Despite the scatter, there is a shift from tensile residual stresses to compressive residual stresses between the TPIF specimen and the comparable SPIF compensated specimen. The residual stresses for 

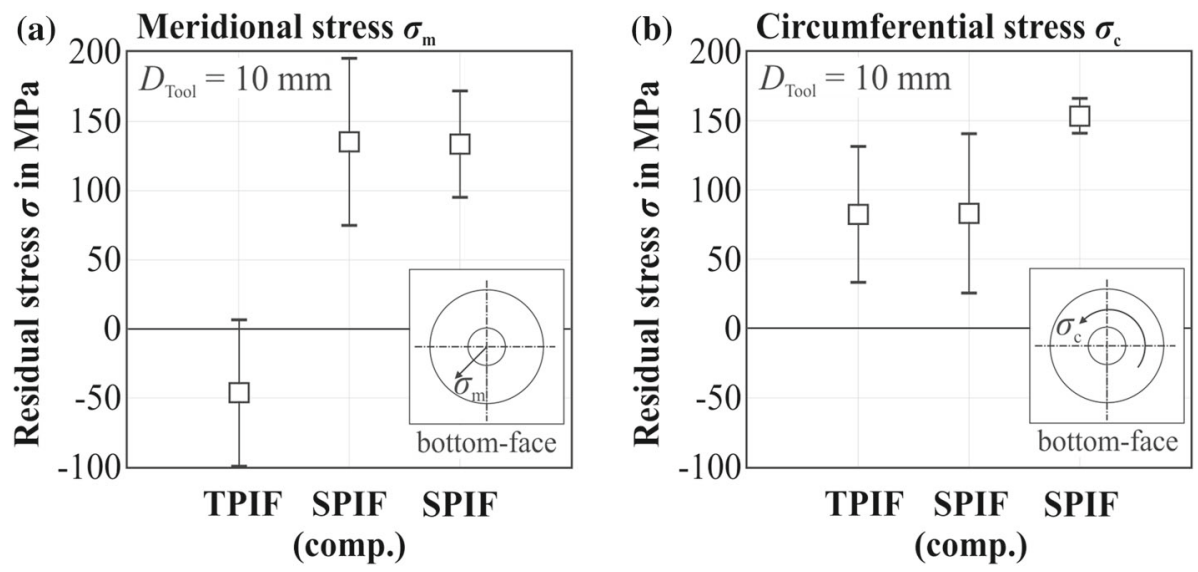

Fig. 13 XRD results at the bottom-face (tool side) in a meridional direction and $\mathbf{b}$ circumferential direction
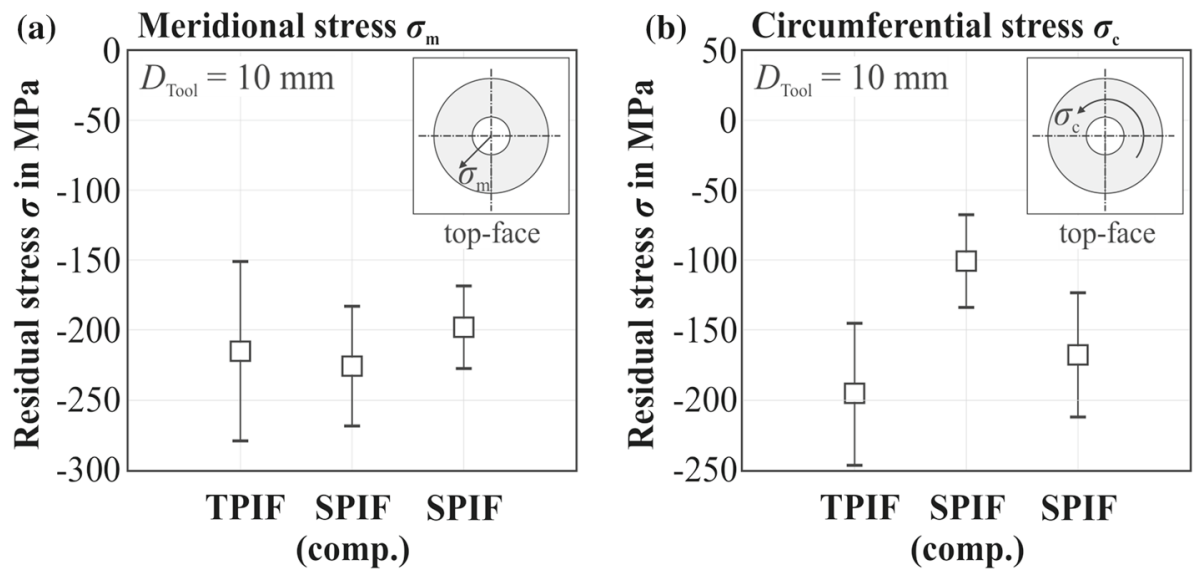

Fig. 14 XRD results at the top-face (non-tool side) in a meridional direction and $\mathbf{b}$ circumferential direction

SPIF and SPIF compensated cones are both tensile with equal amplitudes of approximately $\sigma_{\mathrm{r}}=130 \mathrm{MPa}$. In the truncated cone manufactured using compressive stress-superposed TPIF, significant compressive residual stresses $\left(\sigma_{\mathrm{r}}=-45 \mathrm{MPa}\right)$ occur in meridional direction at the tool side.

The circumferential residual stresses on the tool side (Fig. 13b) are tensile for all three process variants. The highest tensile residual stress can be observed in the SPIF manufactured part with a stress amplitude of approximately $\sigma_{\mathrm{c}}=155 \mathrm{MPa}$. The amount of residual stresses regarding the comparable SPIF compensated geometry is in the same order as the TPIF specimen.

All the measured residual stress states at the non-tool side of the formed cones are compressive tensile residual stresses as shown in Fig. 14. The meridional residual stresses at the non-tool side are high compressive residual stresses in the same range near to.

$\sigma_{\mathrm{r}}=210 \mathrm{MPa}$. The compressive residual stresses in circumferential direction are significantly high for the TPIF specimen, near to $\sigma_{\mathrm{c}}=195 \mathrm{MPa}$. The comparable stresses of the SPIF compensated geometry are lower, at a level close to $\sigma_{\mathrm{c}}=100 \mathrm{MPa}$.

\section{Discussion}

In case of SPIF, the manufactured truncated cone geometry shows poor geometric accuracy compared to TPIF. The compensated SPIF geometry is comparable to the TPIF one. The process forces for the compensated SPIF geometry are on a low level similar to the SPIF process. The thickness reduction of $10 \%$ in the cone wall was less than in TPIF and is in accordance with the sine law. The thickness reduction also means forming-induced hardening and thus leads to an increasing material hardness of 33\% compared to the initial material hardness 
of the aluminum alloy. Regarding the residual stresses, the SPIF and SPIF compensated specimens show high compressive residual stresses on the non-tool side near to the initial yield stress of the material. In case of TPIF using a flexible polyurethane die to superpose compressive stresses, there is a significant effect on the resulting product properties compared to a nearly identical geometry manufactured by SPIF. Due to the higher forming forces to also deform the flexible polyurethane die, up to $80 \%$ higher process forces in $z$-direction compared to SPIF are needed to form the same geometry. Additionally, there is a significant increase in $F_{\mathrm{x}}$ and $F_{\text {y }}$ process forces compared to the very low level of these forces in SPIF. The higher forces and the additional support lead to an increased thickness reduction of $15 \%$ in TPIF with regard to the initial sheet thickness. The thickness reduction results in an additional $12 \%$ hardening of the material compared to the comparable SPIF process. These higher forces result in eight times higher compressive process stresses in through-thickness direction on the tool side as shown numerically. A shift from tensile stresses to compressive stresses in circumferential direction can even be found. In terms of residual stresses, beside the common compressive stresses on the non-tool side and tensile circumferential stresses on the tool side, especially the shift from tensile to compressive stresses in the meridional component on the tool side is a desired outcome of the proposed TPIF compared to SPIF. A possible explanation is that through the both-side compressive contact in TPIF, the material is plasticized more homogeneously through the thickness than in SPIF, leaving less room for local tensile residual stresses to develop. A recent publication [11] showed that these tensile residual stresses on the tool side lead to early failure of the component during fatigue tests. By using SPIF without additional die or support, it is not possible to generate compressive residual stresses thereby adjusting the process parameters. Generating compressive residual stresses by a flexible polyurethane die might thus be beneficial for the fatigue strength of the component. The opposing trend of reduced sheet thickness, increased hardening and reduced tensile residual stresses needs to be further analyzed particularly regarding the product properties to confirm the beneficial effect of a flexible polyurethane die.

\section{Summary and conclusion}

A process enhancement for compressive stress-superposed incremental sheet forming using a geometryindependent polyurethane die was introduced. Beneficial effects of this TPIF process variant on the product properties were shown experimentally as well as numerically. A comparison of two geometrically similar truncated cone geometries demonstrated the possibility of generating compressive meridional residual stresses on the tool side of the cone wall, which is not possible with SPIF. Additionally, the effect of the compressive stress superposition on process forces, sheet thickness and material hardness was analyzed:

- Process forces in $x$-, $y$-, and $z$-direction are increased by using an (elastically) deformable, i.e., flexible die.

- TPIF with the flexible die leads to a decreased sheet thickness.

- An increased material hardness was recorded for TPIF correspondingly.

- The developed knowledge can be used to produce parts with localized properties.

Future studies need to further verify the beneficial effect of forming-induced compressive residual stresses on the product properties. Particularly, the influence of the degree of hardness of the elastomeric die on the component properties and the achievable forming depth need to be analyzed to figure out the process limits.

Acknowledgements The authors would like to thank the German Research Foundation (DFG, Deutsche Forschungsgemeinschaft) for funding the research project TE 508/67-1 part of the priority program SPP 2013 "The utilization of residual stresses induced by metal forming."

Funding Open Access funding enabled and organized by Projekt DEAL. Funded by the German Research Foundation (DFG, Deutsche Forschungsgemeinschaft).

\section{Declaration}

Conflict of interest The authors declare no conflict of interest.

Open Access This article is licensed under a Creative Commons Attribution 4.0 International License, which permits use, sharing, adaptation, distribution and reproduction in any medium or format, as long as you give appropriate credit to the original 
author(s) and the source, provide a link to the Creative Commons licence, and indicate if changes were made. The images or other third party material in this article are included in the article's Creative Commons licence, unless indicated otherwise in a credit line to the material. If material is not included in the article's Creative Commons licence and your intended use is not permitted by statutory regulation or exceeds the permitted use, you will need to obtain permission directly from the copyright holder. To view a copy of this licence, visit http://creativecommons.org/licenses/by/4.0/.

\section{References}

1. Martins, P.A.F., Bay, N., Skjoedt, M., Silva, M.B.: Theory of single point incremental forming. CIRP Ann. Manuf. Technol. 57(1), 247-252 (2009)

2. Bambach, M., Hirt, B., Ames, J.: Modeling of optimization strategies in the incremental CNC sheet metal forming process. AIP Conf. Proc. 712, 969-1974 (2004)

3. Emmens, W.C., van den Boogaard, A.H.: An overview of stabilizing deformation mechanisms in incremental sheet forming. J. Mater. Process. Technol. 209, 3688-3695 (2009). https://doi.org/10.1016/j.jmatprotec.2008.10.003

4. Leszak, E.: Apparatus and process for incremental dieless forming. Patent US3342051A1 (1967)

5. Matsubara, S.: A computer numerically controlled dieless incremental forming of a sheet metal. Proc. Inst. Mech. Eng. Part B J. Eng. Manuf. 215, 959-966 (2001)

6. Lu, H., Kearney, M., Wang, C., Liu, S., Meehan, P.A.: Part accuracy improvement in two point incremental forming with a partial die using a model predictive control algorithm. Precis. Eng. J. 49, 179-188 (2017)

7. Hirt, G., Ames, J., Bambach, M.: Basic investigation into the characteristics of dies and support tools used in CNC-incremental sheet forming. IN: Proceedings of the International Deep Drawing Research Group Conference, pp. 341-348 (2006)

8. Jeswiet, J., Micari, F., Hirt, G.: Asymmetric single point incremental forming of sheet metal. CIRP Ann. 54, 88-114 (2005). https://doi.org/10.1016/S0007-8506(07)60021-3

9. Sebastiani, G., Wawrosch, A., Franzen, V., Brosius, A., Tekkaya, A.E.: FlexDie: a flexible tooling concept for incremental sheet forming. Key Eng. Mater. 504, 883-888 (2012)

10. Nourmohammadi, A., Elyasi, M., Mirnia, M.J.: Flexibility improvement in two-point incremental forming by implementing multi-point die. Int. J. Adv. Manuf. Technol. 102, 2933-2952 (2019). https://doi.org/10.1007/s00170-019-03307-y

11. Maßß, F., Dobecki, M., Hahn, M., Reimers, W., Tekkaya, A.E.: Setting component properties in incremental forming. Contributed Papers from Materials Science and Technology, pp. 1176-1182. https://doi.org/10.7449/2019/MST_2019_117 6_1182 (2019)

12. Durante, M., Formisano, A., Langella, A.: The influence of tool rotation on an incremental forming process. J. Mater. Process. Technol. 209, 4621-4626 (2009). https://doi.org/10.1016/j.jmatprotec.2008.11.028

13. Macherauch, E., Müller, P.: Das sin2- $\Psi$ Verfahren von röntgenographischen Eigenspannungen. Zeitschrift für angewandte Physik 13, 305-312 (1961)

14. Lemaitre, J., Chaboche, J.-L.: Mechanics of Solid Materials. Cambridge University Press, Cambridge (2012)

15. Maaß, F., Hahn, M., Tekkaya, A. E.: Interaction of Process Parameters, Forming Mechanisms and Residual Stresses in Single Point Incremental Forming. Metals, https://www.mdpi.com/2075-4701/10/5/656/htm (2020)

16. Mooney, J.: Finite strain constitutive relation for rubber. J. Appl. Phys. 11 (1940)

Publisher's Note Springer Nature remains neutral with regard to jurisdictional claims in published maps and institutional affiliations. 